\title{
Real-Time Detection of Strawberry Powdery Mildew Disease Using a Mobile Machine Vision System
}

\author{
Md Sultan Mahmud ${ }^{1}$, Qamar U. Zaman ${ }^{1}$, Travis J. Esau ${ }^{1, *}$, Young K. Chang ${ }^{1}{ }^{\mathbb{D}}$, G. W. Price ${ }^{1}$ and \\ Balakrishnan Prithiviraj ${ }^{2}$ \\ 1 Department of Engineering, Faculty of Agriculture, Dalhousie University, Truro, NS B2N 5E3, Canada; \\ msultanmahmud@dal.ca (M.S.M.); qzaman@dal.ca (Q.U.Z.); youngchang@dal.ca (Y.K.C.); \\ gprice@dal.ca (G.W.P.) \\ 2 Department of Plant, Food, and Environmental Sciences, Dalhousie University, Truro, NS B2N 5E3, Canada; \\ bprithiviraj@dal.ca \\ * Correspondence: tesau@dal.ca; Tel.: +1-902-893-3055
}

Received: 20 June 2020; Accepted: 13 July 2020; Published: 16 July 2020

\begin{abstract}
Strawberry cropping system relies heavily on proper disease management to maintain high crop yield. Powdery mildew, caused by Sphaerotheca macularis (Wall. Ex Fries) is one of the major leaf diseases in strawberry which can cause significant yield losses up to $70 \%$. Field scouts manually walk beside strawberry fields and visually observe the plants to monitor for powdery mildew disease infection each week during summer months which is a laborious and time-consuming endeavor. The objective of this research was to increase the efficiency of field scouting by automatically detecting powdery mildew disease in strawberry fields by using a real-time machine vision system. A global positioning system, two cameras, a custom image processing program, and a ruggedized laptop computer were utilized for development of the disease detection system. The custom image processing program was developed using color co-occurrence matrix-based texture analysis along with artificial neural network technique to process and classify continuously acquired image data simultaneously. Three commercial strawberry field sites in central Nova Scotia were used to evaluate the performance of the developed system. A total of 36 strawberry rows ( 1.06 ha) were tested within three fields and powdery mildew detected points were measured manually followed by automatic detection system. The manually detected points were compared with automatically detected points to ensure the accuracy of the developed system. Results of regression and scatter plots revealed that the system was able to detect disease having mean absolute error values of 4.00,3.42, and 2.83 per row and root mean square error values of $4.12,3.71$, and 3.00 per row in field site-I, field site-II, and field site-III, respectively. The slight deviation in performance was likely caused by high wind speeds $\left(>8 \mathrm{~km} \mathrm{~h}^{-1}\right)$, leaf overlapping, leaf angle, and presence of spider mite disease during field testing.
\end{abstract}

Keywords: machine vision; powdery mildew; real-time sensing; texture analysis; artificial neural networks

\section{Introduction}

Powdery mildew (Sphaerotheca macularis) is a serious disease affecting strawberry production in both warm and dry climates [1] and reduces crop yields by causing decreased fruit set, inadequate ripening, poor flavor, fruit cracking and deformation, and reducing postharvest storage time [2]. Powdery mildew (PM) can be remarkably problematic when strawberry plants are grown in greenhouses or polythene tunnels, both of which are conducive to severe outbreaks of PM [3]. Generally, strawberries are commercially grown on raised beds covered with impermeable polythene mulch/tunnel in outdoor fields. The white patches of mycelia are the initial symptoms of PM disease, which appear on upper 
and/or lower strawberry leaf surfaces during disease progression [4]. The PM disease symptoms primarily appear on young leaves [5], scatter through petioles, runners, flowers, and fruits except roots [6]. The conidial germination of PM disease is optimally grown when the temperature ranges between 15 and $25^{\circ} \mathrm{C}$ and relative humidity ranges from $75 \%$ to $98 \%$ [5]. When the PM disease becomes severe, the fruit may crack, causing exposure to secondary infections [7] and causing yield losses of up to $70 \%$ [8]. To date, visual observation is still the only method to measure the presence of PM disease in strawberry cultivation systems. According to Zhang et al. [9], the traditional visual inspection of diseases is a time-consuming and labor-intensive approach and is also quite impractical on large farms. Thus, an automated detection system is vital for strawberry growers to inspect PM disease occurrence in field.

Over the last decade, image processing-based machine vision technologies have been effectively used for fast and accurate plant disease monitoring and detection within fields [10,11]. Imaging in the open field is a challenge compared to laboratory conditions due to uncontrollable environmental factors such as illumination variation, leaf density and overlap, leaf angle, and wind speed [12]. Open fields can result in adverse operating environments, offering random variability due to terrain and weather, as well as imperfections of input images that can easily influence the accuracy and precision of machine vision systems [13]. Pajares et al. [14] provided guidelines for selection of appropriate agricultural machine vision systems based on lighting conditions in outdoor environments, irregular terrain, or different plant growth stages for optimum performance. Lee et al. [15] developed a real-time machine vision system, which was only capable of correctly detecting $47.6 \%$ of weeds with $24.2 \%$ oversprayed tomato plants in outdoor field conditions. Sabzi et al. [16] proposed a machine vision system based on hybrid artificial neural network-harmony search classifiers for automatic segmentation of plants under different illumination conditions and claimed it could be applied under all field applications with higher accuracies. However, reliable studies have not been conducted using mixed canopy conditions that are common in agricultural fields. Therefore, a real-time machine vision system that is able to detect plant disease under mixed canopy field conditions needs to be developed.

Several attempts applying a color co-occurrence matrix (CCM)-based image processing technique for crop disease detection have been reported by various researchers, with promising results under different cropping systems [10,17-22]. Table 1 summarizes the accuracies obtained from using a CCM-based textural analysis method for disease detection in crops.

Pydipati et al. [17] utilized a CCM-based textural analysis method to extract important features aimed at identifying diseased and normal citrus leaves. According to the authors, the CCM, along with a back-propagation neural network algorithm, achieved over $90 \%$ accurate detections in all cases used for analysis. In follow-up work, Pydipati et al. [18] used a CCM-based classification algorithm to detect healthy and greasy spot, melanose, and scab disease-affected citrus leaves. Results of their laboratory trials showed that the algorithm was able to achieve classification accuracies of over $95 \%$ for all classes. Other studies have successfully achieved $93 \%$ detection for tomato leaf disease [19], using a CCM-based texture analysis algorithm along with a neural network classifier, and $91 \%$ accuracy in classifying different types of nursery stock [23], using a CCM-based algorithm. CCM-based custom image processing is not a novel approach but to date limited research has been conducted on detection of strawberry powdery mildew, which causes severe yield crop losses around the world. Current detection of PM, specifically in strawberries, using machine vision-based automated techniques have largely been conducted under laboratory or controlled conditions [21,25]. Yang et al. [25] demonstrated the capacity to recognize strawberry PM disease from single harvested strawberry leaf using a convolutional neural network. Mahmud et al. [21] analyzed single leaf images to detect PM disease in strawberry under controlled environmental conditions during image acquisition. Real-time detection of weeds and disease poses significant challenges and only a few have been successfully evaluated in agricultural fields. 
Based on the success of PM detection under controlled conditions in previous work, the goal of this study was to evaluate how a mobile machine vision system would perform in real-time detection of PM in field-based strawberry production systems.

Table 1. Summary of disease detection accuracies using color co-occurrence matrix (CCM)-based textural analysis in different cropping systems.

\begin{tabular}{|c|c|c|c|}
\hline $\begin{array}{c}\text { Diseases } \\
\text { Detection/Classification }\end{array}$ & Image Processing & Accuracy & References \\
\hline $\begin{array}{l}\text { Normal and greasy spot, } \\
\text { melanose, and scab citrus } \\
\text { leaf diseases }\end{array}$ & $\begin{array}{c}\text { CCM and a back-propagation } \\
\text { neural network }\end{array}$ & Over $90 \%$ & [17] \\
\hline $\begin{array}{c}\text { Normal and greasy spot, } \\
\text { melanose, and scab citrus } \\
\text { leaf diseases }\end{array}$ & $\begin{array}{l}\text { CCM features extract from } \\
\text { converted hue, saturation and } \\
\text { value (HSV) color space }\end{array}$ & Over $95 \%$ & [18] \\
\hline $\begin{array}{l}\text { Early scorch, cottony mold, } \\
\text { ashen mold, late scorch, and tiny } \\
\text { whiteness diseases of tomato } \\
\text { and other crops }\end{array}$ & $\begin{array}{l}\text { CCM along with neural } \\
\text { network classifier }\end{array}$ & $93 \%$ & [19] \\
\hline $\begin{array}{l}\text { Early scorch, cottony mold, } \\
\text { ashen mold, late scorch, and tiny } \\
\text { whiteness diseases of tomato } \\
\text { and other crops }\end{array}$ & CCM and neural network model & $83-94 \%$ & [10] \\
\hline Nursery stock & $\mathrm{CCM}$ and discriminant analysis & $90.9 \%$ & [23] \\
\hline Powdery mildew of strawberry & $\begin{array}{l}\text { CCM along with support vector } \\
\text { machine algorithm (SVM) }\end{array}$ & $91.86 \%$ & [21] \\
\hline $\begin{array}{l}\text { Yellow spots, brown spots, } \\
\text { scorch and late scorch diseases } \\
\text { of banana, lemon, and bean }\end{array}$ & CCM texture analysis with SVM & $94 \%$ & [20] \\
\hline $\begin{array}{l}\text { Scorch and spot classification of } \\
\text { plant leaves }\end{array}$ & $\begin{array}{c}\mathrm{CCM} \text { and artificial } \\
\text { neural network (ANN) }\end{array}$ & $100 \%$ & [24] \\
\hline
\end{tabular}

\section{Materials and Methods}

\subsection{Machine Vision System Development}

A mobile machine vision system was developed by fabricating a custom platform (width $\times$ length $\times$ height: $2.184 \mathrm{~m} \times 1.219 \mathrm{~m} \times 0.737 \mathrm{~m}$ ) using locally sourced bicycle components to minimize the cost (Figure 1).

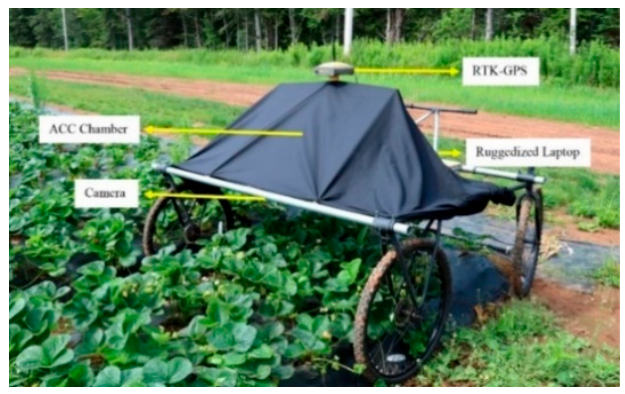

Figure 1. Mobile platform of real-time machine vision system with artificial cloud lighting condition (ACC) chamber.

The custom-based machine vision system was fabricated by modifying image acquisition hardware, as defined in Mahmud et al. [22], in order to effect real-time detection in the field. The system was 
manually propelled by pushing an integrated handle bar. An artificial cloud lighting condition (ACC) system was mounted on the mobile platform to minimize the variation of illumination during image acquisition in the field [22]. The ACC was made with a black cloth cover to avoid direct sunlight during image acquisition (Figure 1). The light illumination readings inside of the ACC chamber ranged from 800 to $900 \mathrm{~lx}$ during field trials. The system was designed to operate within single strawberry rows (1.219 $\mathrm{m}$ width) and slim bicycle wheels were used to minimize the damage on strawberry runners during the study. The system consisted of two $\mu$ Eye $1240 \mathrm{LE} / \mathrm{C}$ color cameras (IDS Imaging Development System Inc., Woburn, MA, USA), a HiPer ${ }^{\circledR}$ Lite + RTK-GPS (Topcon Positioning Systems Inc., Livermore, CA, USA) for georeferencing and a ruggedized laptop computer (Toshiba Corporation, Minato, Tokyo, Japan). Each of the cameras acquired 24-bits blue-green-red (BGR) $640 \times 256$ pixels images covering a $0.6096 \mathrm{~m} \times 0.2438 \mathrm{~m}$ (length $\times$ width) area of interest (AOI) of each section (half of row) in strawberry row (Figure 2).

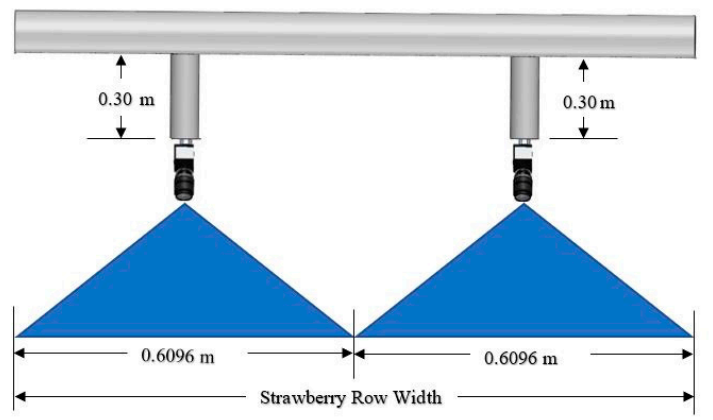

Figure 2. Field of view of two cameras.

The AOI was used to minimize the barrel effect caused by the wide-angle lens by extracting from the center of the full frame images of $1280 \times 1024$ pixels. The wide-angle field of view lenses (LM4NCL, Kowa Optimed Inc., Torrance, CA, USA) were set up to a fixed aperture (f/4.0) and infinity focus with a $3.5 \mathrm{~mm}$ focal length. The cameras were set up with a $30^{\circ}$ inclination from the vertical $Z$-axis (downward), as shown in the Figure 3, for acquiring suitable images for PM detection in the field. The inclination of $30^{\circ}$ was chosen based on testing different angles prior to the start of the study. Images acquired with a $30^{\circ}$ inclination facing the driving direction made the PM symptoms more visible since the disease is located under the leaves initially and infected leaf edges may also roll upward. Examples of images captured using a two-camera set up (one is $90^{\circ}$ vertically downward and another is $30^{\circ}$ inclination with the vertically downward-axis) are shown in Figure 4.

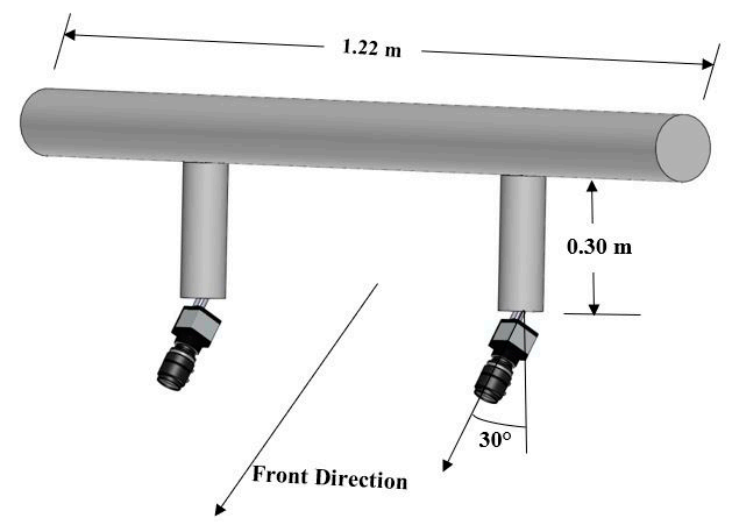

Figure 3. Camera setup for image acquisition during field experiments. 


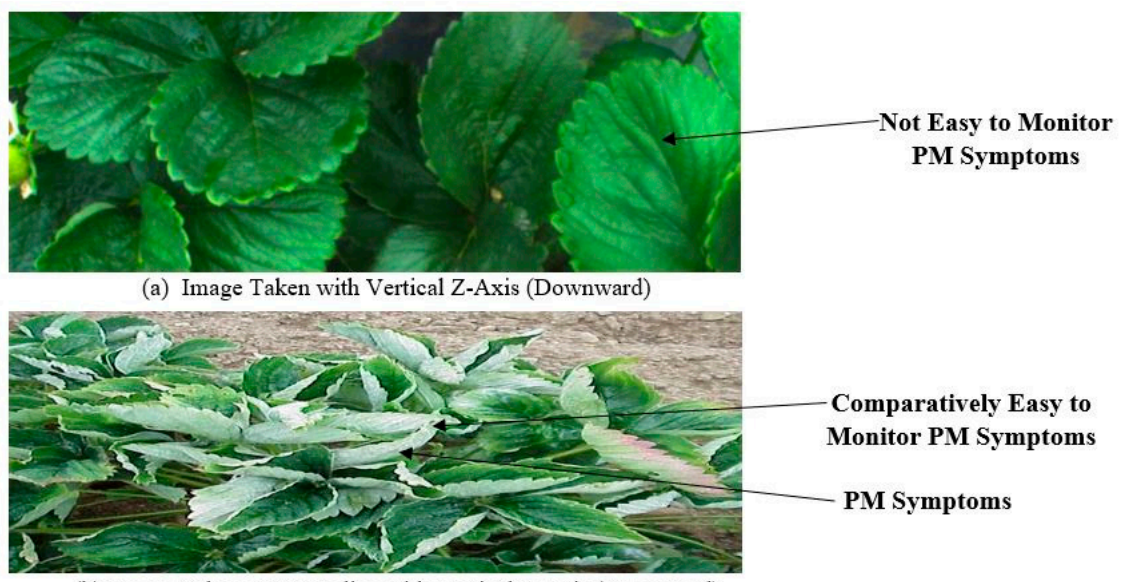

(b) Image Taken at $30^{\circ}$ Incline with Vertical Z-Axis (Downward)

Figure 4. Images captured at two different camera angles prior to study to test acquisition quality (a) image taken with vertical z-axis (downward) (b) image taken at $30^{\circ}$ incline with vertical $\mathrm{z}$-axis (downward).

Cameras were connected directly to the laptop computer using universal serial bus (USB) cables. Image acquisition by the cameras were conducted at a travelling speed rate of 25 frames per second (FPS) during the experiments. An image was extracted from every 15 frames to avoid overlapped areas between images. The cameras had a $0.3 \mathrm{~m}$ working depth from the camera sensor to leaf canopy. The system speed was manually controlled at $1.50 \pm 0.40 \mathrm{~km} \mathrm{~h}^{-1}$ and was maintained constant during the study by continuous monitoring of the graphical user interface (GUI) display. The system speed (in knots) was parsed from RTK-GPS string and converted into metric units (speed $\left(\mathrm{ms}^{-1}\right)=$ $0.51444 \times$ speed (knots)). The $0.30 \mathrm{~m}$ working depth and image acquisition speed of $1.50 \mathrm{~km} \mathrm{~h}^{-1}$ was previously determined to be optimum for strawberry powdery mildew detection [22]. Digital gain and exposure time were automatically controlled by autogain control and autoexposure shutter. The RTK-GPS antenna was mounted above the cameras to simultaneously record the coordinates. The RTK-GPS position of the images was continuously stored in laptop computer by using National Marine Electronics Association (NMEA-0183) standard code sentences. The program was designed to only store the powdery mildew image location, when it was detected, into a comma-separated values (CSV) file.

A real-time strawberry powdery mildew disease detection algorithm was developed in C\# (sharp) using Visual Studio 2017 (Microsoft, Redmond, WA, USA). The algorithm was programmed to process images and differentiate powdery mildew affected leaves from healthy or other diseased leaves (that did not retain similar features to PM). The image processing steps started with a conversion of the acquired blue, green and red (BGR) image into a green ratio, and hue, saturation and intensity (HSI) image. According to Meng et al. [26], the HSI color space works better compared to RGB (red, green, and blue) and YUV (luminance, chrominance, and chroma) for image processing under field conditions. The hue channel from HSI color space represents the purity of color, such as pure blue $(b)$, green $(g)$, and red $(r)$ in terms of degree, whereas saturation represents the measure, from 1 to 0 , to which pure color is diluted by a neutral color [27]. The $b, g$, and $r$ intensity levels of individual pixel of an image were utilized to calculate the hue $(H)$, saturation $(S)$, and intensity $(I)$ components of that pixel by using the geometrical transformation relationships. These relationships were defined by the International Commission on Illumination (CIE) chromaticity diagram [27]. A color conversion was performed for this study from BGR to HSI color plane on input images. Each input image was used to create three two-dimensional arrays in the process of CCM, color co-occurrence matrix. The pixel intensity of each 
array was applied for CCM construction from each color plane. The $H, S$, and $I$ images were converted using Equations (1)-(4) suggested by [27].

$$
\theta_{h}=\cos ^{-1}\left\{\frac{\frac{1}{2}[(r-g)+(r-b)]}{\left[(r-g)^{2}+(r-g)(g-b)\right]^{\frac{1}{2}}}\right\}
$$

where, $\theta_{h}$ is the angle, and hue $(H)$ color plane was calculated based on angle $\left(0-360^{\circ}\right)$ of circle which was normalized in the range between 0 and 1 . This normalized angle was then linearly transformed to 256 different intensity levels for calculating the $H$ of particular pixel depending upon its $r, g$, and $b$ components (Equation (2)).

$$
\begin{aligned}
& H=\left\{\begin{array}{c}
\frac{\theta_{h}}{360} \times 255 \text { if } b \leq g \\
\frac{360-\theta_{h}}{360} \times 255 \text { if } b>g
\end{array}\right\} \\
& S=255 \times\left\{1-\frac{3}{(r+g+b)}(\operatorname{Min}(r, \operatorname{Min}(g, b)))\right\}
\end{aligned}
$$

where, $S$ is the saturation color plane.

$$
I=\frac{r+g+b}{3}
$$

The ratio used was $(G \times 255)(B+G+R)^{-1}$ and a manually obtained threshold $(>86)$ for conversion to g-ratio images. The g-ratio images were masked with the original images to remove the background. Another thresholding was conducted with the masked image along with the manually obtained threshold (red > 190 and red <220, green $>220$ and green $<245$, and blue $>180$ and blue $<200$ ) to obtain the final image for extracting valuable features. Color co-occurrence matrices (CCMs) [23] were constructed from converted images, followed by textural features extraction. The CCMs were constructed with four converted images from one image followed by extracting a set of 10 features from the individual CCM. Since frequency in the CCMs is a function of the angular relationship and distance between neighboring pixels, in this research, an angular relationship $\left(o_{a}\right)$ of $0^{\circ}$ and a displacement vector $\left(d_{v}\right)$ of 1 pixel were selected for CCM construction. The displacement vector of 1 pixel was selected, as it provided exceptional results when varied between 1 and 5 [28]. The features data were normalized and resulting normalization of each CCM value varied from 0 to 1 . The CCMs were normalized by dividing the individual entity in the CCM matrix by the total number of pairs in each matrix using the relationship presented in Equation (5) [29].

$$
N(a, f)=\frac{n(a, f, 1,0)}{\sum_{a=0}^{F-1} \sum_{f=0}^{F-1} n(a, f, 1,0)}
$$

where, $N(a, f)$ is a normalized CCM, $n(a, f)$ is a marginal probability function, $a$ is the intensity level at a certain pixel, $f$ is another matching intensity level with displacement vector, $d_{v}=1$ and an orientation angle $o_{a}=0$, and the denominator of the equation, sum of $n(a, f)$, is the total number of pairs in the matrix with specific orientation and displacement vector.

A total of 40 textural features were extracted from an individual image after constructing the CCM but 23 features were specifically chosen to detect PM disease. The textural features were extracted by equations used from Shearer and Holmes [23] and presented in Table 2.

The 23 textural features were chosen due to their optimal performance compared to extracted 50 features for powdery mildew disease detection reported in laboratory experiments by Mahmud et al. [22] using stepwise discriminant analysis. The selected features are presented in Table 3 . 
Table 2. Textural features equations suggested by [23].

\begin{tabular}{|c|c|}
\hline Features Name & Equation [v] \\
\hline Contrast & $\sum_{|a-f|=0}^{F-1}(a-f)^{2} \sum_{a=0}^{F-1} \sum_{f=0}^{F-1} N(a, f)$ \\
\hline Homogeneity & $\sum_{a=0}^{F-1} \sum_{f=0}^{F-1} N(a, f) \frac{1}{1+|a-f|}$ \\
\hline Entropy & $\sum_{a=0}^{F-1} \sum_{f=0}^{F-1} N(a, f) \operatorname{In} N(a, f)$ \\
\hline Dissimilarity & $\sum_{a=0}^{F-1} \sum_{f=0}^{F-1} N(a, f)|a-f|$ \\
\hline Angular second moment & $\sum_{a=0}^{F-1} \sum_{f=0}^{F-1} N(a, f)^{2}$ \\
\hline Inverse difference moment & $\sum_{a=0}^{F-1} \sum_{f=0}^{F-1} \frac{N(a, f)}{1+(a-f)^{2}}$ \\
\hline Average & $\sum_{a=0}^{F-1} f N_{x}(a)$ \\
\hline Sum of squares & $\sum_{a=0}^{F-1}(a-\mu)^{2} N_{x}(a)$ \\
\hline Product moment & $\sum_{a=0}^{F-1} \sum_{f=0}^{F-1} N(a, f)(a-\mu)(f-\mu)$ \\
\hline Correlation & $\sum_{a=0}^{F-1} \sum_{f=0}^{F-1} N(a, f) \frac{\left(a-\mu_{a}\right)\left(f-\mu_{f}\right)}{\sigma_{a} \sigma_{f}}$ \\
\hline
\end{tabular}

[v] $F$ is the total number of intensity levels, $N(a, f)$ is the $(a, f)$ th entry in a normalized CCM, $\mu$ is the mean, $\mu_{a}$ is the mean of row, $\mu_{f}$ is the mean of column, $\sigma_{a}$ and $\sigma_{a}$ are the standard deviation along the $a$ th row and $f$ th column of $\mathrm{N}$ $(a, f)$, respectively, and $\mathrm{N}_{x}(a)$ was obtained by summation of CCM values in $a$ th row.

Table 3. Selected textural features.

\begin{tabular}{|c|c|c|c|c|c|c|c|c|c|c|}
\hline \multirow{2}{*}{$\begin{array}{l}\text { Converted } \\
\text { Images }\end{array}$} & \multicolumn{10}{|c|}{ Extracted Textural Features [S] } \\
\hline & Con & Hom & Ent & Dis & A2M & IDM & Avg & SoS & PM & Cor \\
\hline G-ratio & $\checkmark$ & $\checkmark$ & & $\boldsymbol{V}$ & & & & & $\checkmark$ & $\boldsymbol{V}$ \\
\hline Hue & $\checkmark$ & $\checkmark$ & $\checkmark$ & $\boldsymbol{V}$ & & & $\checkmark$ & & & $\boldsymbol{V}$ \\
\hline Saturation & $\boldsymbol{\sim}$ & $\checkmark$ & & $\boldsymbol{V}$ & & & $\boldsymbol{\sim}$ & & $\boldsymbol{V}$ & $\boldsymbol{v}$ \\
\hline Intensity & $\checkmark$ & $\checkmark$ & & $\boldsymbol{\sim}$ & & & $\checkmark$ & & $\boldsymbol{v}$ & $\boldsymbol{V}$ \\
\hline
\end{tabular}

[S] Con: contrast, Hom: homogeneity, Ent: entropy, Dis: dissimilarity, A2M: angular second moment, IDM: inverse difference moment, Avg: average, SoS: sum of square, PM: product moment, and Cor: correlation.

Dandawate and Kokare [30] reported that a combination of feature extraction using CCM and artificial neural networks (ANN) machine learning was suitable for detection of different plant diseases. Among the many supervised machine learning technologies available, using co-occurrence-based feature extraction with ANN generated better results when dealing with different leaf angles or positions, which is likely to occur under field conditions [31]. Therefore, the CCM extracted features were analyzed for PM by using the ANN-based machine learning classifier. ANN-based machine learning was also chosen due to its superior performance relative to support vector machines and k-nearest neighbor for powdery mildew detection reported in controlled experiments [32]. Peltarion Synapse (Peltarion Corp., Stockholm, Sweden) software was used to select the optimal ANN model architecture using our extracted features data. A total of 20 combinations of model architectures were tested and 4 optimal architectures were selected (Table 4). 
Table 4. Tested mathematical functions at an epoch size of 15,000 with normalized data.

\begin{tabular}{|c|c|c|c|c|c|c|c|c|}
\hline \multirow{2}{*}{ Model Structures } & \multicolumn{2}{|c|}{ Tanh Sigmoid } & \multicolumn{2}{|c|}{ Logistic Sigmoid } & \multicolumn{2}{|c|}{ Linear } & \multicolumn{2}{|c|}{ Exponential } \\
\hline & MAE & RMSE & MAE & RMSE & MAE & RMSE & MAE & RMSE \\
\hline $\begin{array}{c}1 \mathrm{~W}(23 / 23) \text { and } 1 \mathrm{~F} \\
(23 / 1) 23 \text { inputs } 1 \\
\text { output }\end{array}$ & 0.040 & 0.058 & 0.073 & 0.082 & 0.265 & 0.343 & 1.639 & 1.973 \\
\hline $\begin{array}{l}1 \mathrm{~W}(23 / 23) 1 \mathrm{~W} \\
(23 / 23) 1 \mathrm{~F}(23 / 1) 23 \\
\text { inputs } 1 \text { outputs }\end{array}$ & 0.008 & 0.010 & 0.054 & 0.068 & 0.146 & 0.211 & 0.683 & 0.769 \\
\hline $\begin{array}{c}1 \mathrm{~W}(23 / 46) \text { and } 1 \mathrm{~F} \\
(46 / 1) 23 \text { inputs } 1 \\
\text { output }\end{array}$ & 0.004 & 0.005 & 0.017 & 0.021 & 0.119 & 0.193 & 0.614 & 0.687 \\
\hline $\begin{array}{l}1 \mathrm{~W}(23 / 46) 1 \mathrm{~W} \\
(46 / 46) 1 \mathrm{~F}(46 / 1) 23 \\
\text { inputs } 1 \text { output }\end{array}$ & 0.003 & 0.004 & 0.010 & 0.023 & 0.102 & 0.179 & 0.528 & 0.692 \\
\hline
\end{tabular}

A back-propagation artificial neural network (BP-ANN) algorithm was applied to train the proposed network architectures. Four different transfer functions, including the tanh sigmoid, exponential, logistic sigmoid, and linear functions were used to translate the input signals into output signals ranging from 0 to 2 (i.e., 0,1 , and 2). The extracted textural features were selected as inputs for the input layer and corresponding healthy or disease labels (powdery mildew and other diseases) were established as an output in the output layer. All the settings of developed models were kept constant, the mathematical functions were changed, and finally mean absolute error (MAE) and root mean square error (RMSE) were recorded to find an optimal mathematical function for this study. A 1W (23/46) 1W (46/46) 1F (46/1) ANN model architecture with a tanh sigmoid transfer function was chosen having the epoch size of 15,000. Farooque et al. [33] also developed an optimal ANN model with an epoch size of 15,000 and reported that the model was more suitable in capturing nonlinearity of relationships between variables. A 6000 image dataset was analyzed $(60 \%$ for training and $40 \%$ for validation) to select an optimal model architecture. Three categories of images, e.g., healthy, powdery mildew affected, and other disease affected, were collected from 10:00 a.m. to 4:00 p.m. Upon selection of an optimal ANN model architecture, the model was deployed from Peltarion Synapse software as a dynamic link library file (dll) file. The deployed dll file used by the real-time powdery mildew disease detection algorithm ensured real-time selection of one of the three categories, i.e., powdery mildew affected, healthy, or other disease affected leaves. The algorithm had a statement (is the image powdery mildew affected?) to save the georeferenced coordinates in a CSV file of leaves identified as PM affected. The detection results of georeferenced coordinates location were imported into ArcGIS 10.5 computer software (ESRI, Redlands, CA, USA) for prescription mapping. Overview of the real-time detection algorithm is presented in Figure 5. 


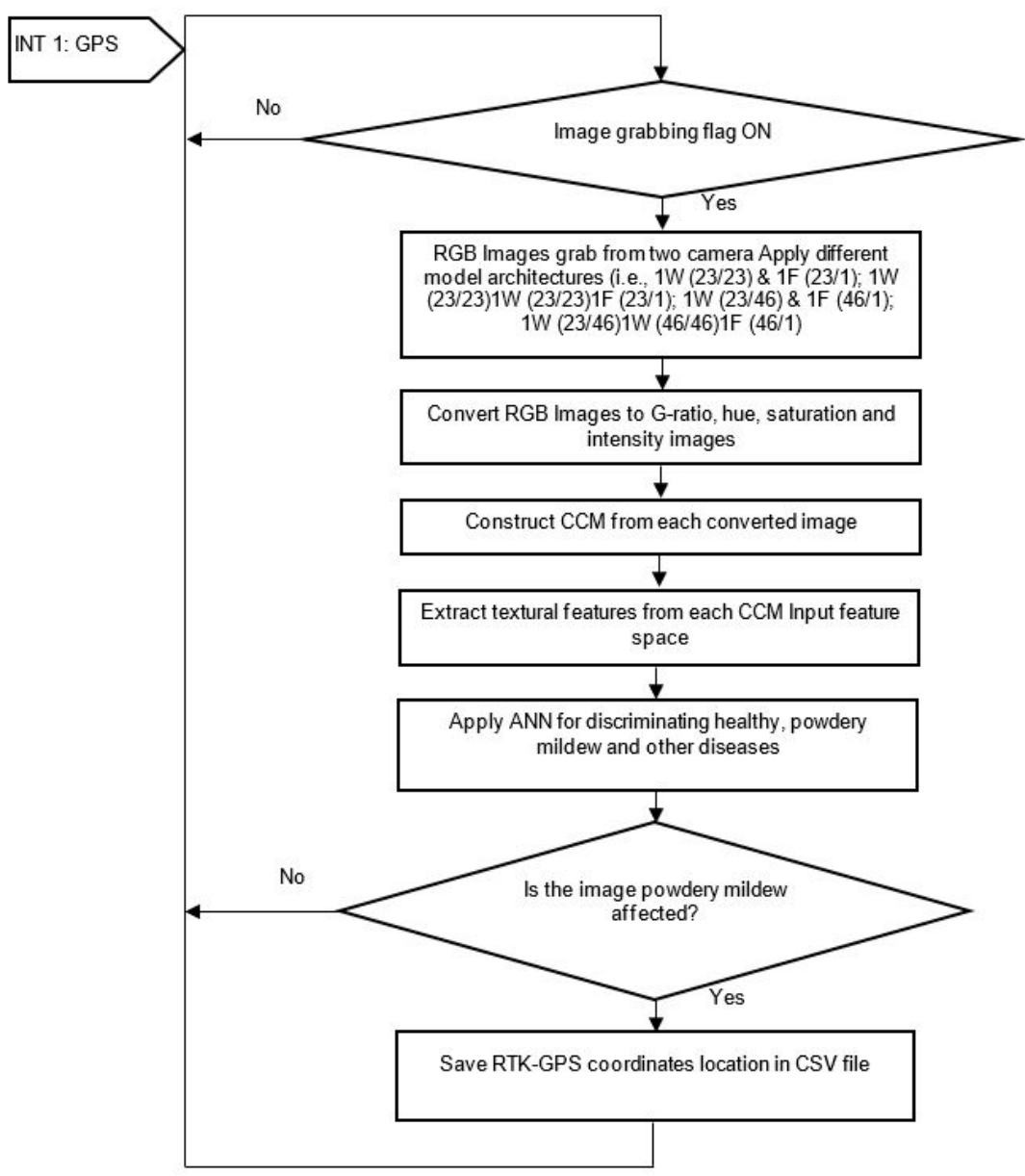

Figure 5. Flow chart of real-time strawberry powdery mildew disease detection algorithm.

\subsection{Field Evaluation of Machine Vision System for Strawberry Powdery Mildew Detection}

Testing of the real-time machine vision system on powdery mildew disease detection in commercial strawberry fields was carried out on the 6, 7, and 13 August 2018. The commercial strawberry operations located in Debert, Nova Scotia, provided fields under production for the evaluation of the real-time system. The tests were conducted on sunny days, with temperatures ranging from 20 to $32{ }^{\circ} \mathrm{C}$, relative humidity $\left(\mathrm{R}_{\mathrm{H}}\right)$ from $50 \%$ to $82 \%$, and wind speeds from 3 to $14 \mathrm{~km} \mathrm{~h}^{-1}$ [34].

Three strawberry field sites were selected in Debert, Nova Scotia, to evaluate the performance of machine vision-based powdery mildew disease detection system. A commercial 12-hectare strawberry farm was used to conduct this study. The field sizes were 1.3 ha each (area) located in Debert site I (field 1; 45.429318 ${ }^{\circ} \mathrm{N}, 63.483843^{\circ} \mathrm{W}$ ), Debert site II (field 2; $45.429611^{\circ} \mathrm{N}, 63.48114^{\circ} \mathrm{W}$ ), and Debert site III (field 3; $45.429098^{\circ} \mathrm{N}, 63.480276^{\circ} \mathrm{W}$ ). All fields were cultivated with an Albion strawberry variety. Albion is a day-neutral or everbearing strawberry variety that grows quickly to about 12 inches $(0.30 \mathrm{~m})$ in height, with a spread of $12-24$ in $(0.30-0.60 \mathrm{~m})$. They are high yielding and everbearing, which means they usually provide flower and fruit continuously from late spring into the fall. The fields have been cultivated in strawberries over the past few years and each maintained commercial management practices including mowing, pruning, fertilizing, and application of herbicides, pesticides, fungicide, etc. A total of 12 randomly selected strawberry rows were tested in each field (Figure 6). The strawberry rows evaluated had dimensions of $1.22 \mathrm{~m} \times 220 \mathrm{~m}$ (wide $\times$ length) for field site-I and $1.22 \mathrm{~m} \times 180 \mathrm{~m}$ for field site-II and field site-III with a $0.31 \mathrm{~m}$ buffer between rows (Figure 6). 


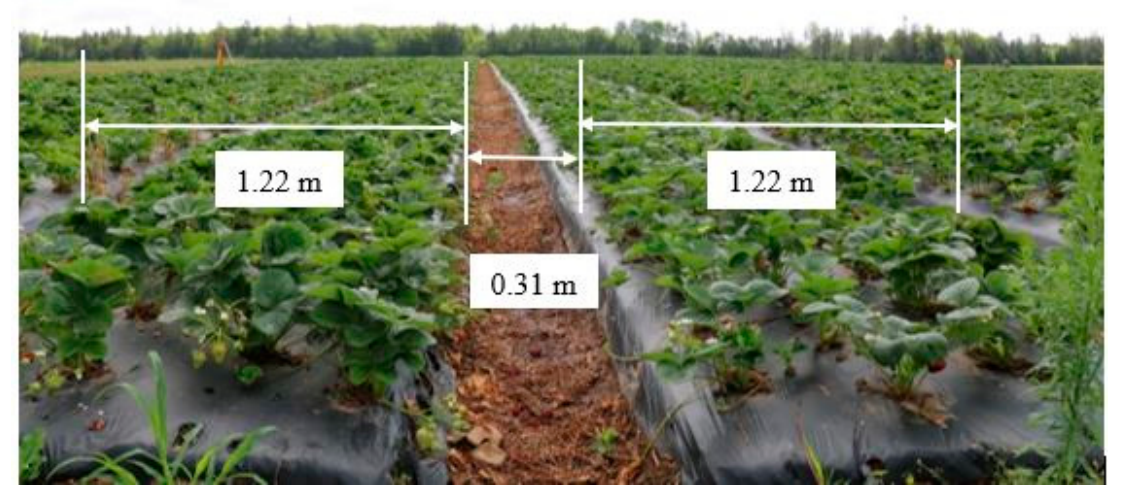

Figure 6. Experimental strawberry field (1.22 $\mathrm{m}$ in row width with a $0.31 \mathrm{~m}$ buffer between rows).

Manual detection of PM disease was conducted for each experimental field based on recommendations from two experienced field scouts who checked for symptoms including white patches of mycelium on the upper leaf surface, roll upward leaf edges, and reddish irregular spots on leaf. Manual detection was conducted by carefully confirming all the symptoms of strawberry PM, especially checking white patches with roll edges leaves throughout the experiments. The detected points were marked by inserting red flags. The number of detected points of powdery mildew affected plants in a single row was calculated manually recorded in a paper notebook (Hilroy, Mississauga, ON, Canada) after counting. The locations of the detected points were also recorded using a ProMark3 mobile mapper (Thales Navigation, Santa Clara, CA, USA).

The machine vision system was deployed over individual rows of strawberry plants for continuous image acquisition by the two cameras. A total of 36 rows were covered over 3 strawberry fields (12 rows each) in this study. The images were processed through texture analysis by CCM and followed by detection using the ANN classifier. A step-by-step real-time strawberry PM disease detection process of an image is presented in Figure 7. The average processing time for an image was $7648 \mu \mathrm{s}(\sim 0.0076 \mathrm{~s})$. The powdery mildew detected leaf image locations (latitude and longitude) were saved automatically to a CSV file using a function in the custom software. Manually and automatically detected points were compared by manually counting points to evaluate the outcomes of the system. The detected points were mapped to create prescription map using the co-ordinates (longitude and latitude) collected from RTK-GPS and mobile mapper.

The software interface of the machine vision system was developed using Microsoft Visual Studio 2017 (Microsoft Corp, Redmond, WA, USA) (Figure 8).

Communication between the RTK-GPS and laptop computer was established using a serial link setting (COM Port 1, baud rate 9600 bps, stop bit none, and parity bit 1). The speed of the system was calculated from NMEA-0183 standard code system directly from the RTK-GPS data displayed in GUI (Figure 8). The latitude and longitude were also recorded from standard code from the RTK-GPS. The checkbox of camera selection was added to control the two cameras used for real-time image acquisition. Although the experiments used four processed images from one camera, two picture boxes (for one camera) were added in the real-time software due to a lack of space in the GUI display. The processed g-ratio and hue images were displayed from both cameras. The program was able to process the images to differentiate powdery mildew leaf images in the strawberry fields in real-time from both images taken by the two cameras. The system performance was evaluated by correlating the manual detection results with the automatic system detection results from both cameras in all the fields. The performance of the developed system is also evaluated by calculating recall, precision, and 
F-measure using relationship presented in Equations (6)-(8), respectively. Prescription maps were developed from the experimental data using ArcGIS 10.5 software.

$$
\begin{gathered}
\text { Recall }=\frac{T_{p}}{T_{p}+F_{n}} \times 100(\%) \\
\text { Precision }=\frac{T_{p}}{T_{p}+F_{p}} \times 100(\%) \\
F_{\varepsilon}=\frac{(1+\varepsilon) \times \text { Recall } \times \text { Precision }}{\varepsilon \times \text { Precision }+ \text { Recall }}
\end{gathered}
$$

where, $T_{p}$ is the correctly detected points of PM disease, $F_{p}$ is the number of healthy and other diseases points that are falsely classified as PM disease, and $F_{n}$ is the number of points of PM disease that are falsely detected as healthy or other disease. $F_{\sigma}$ is the F-measure value representing accuracy using recall and precision relationship, and $\varepsilon$ is a non-negative real value, we set $\varepsilon=0.80$ in this study to weigh recall more than precision.

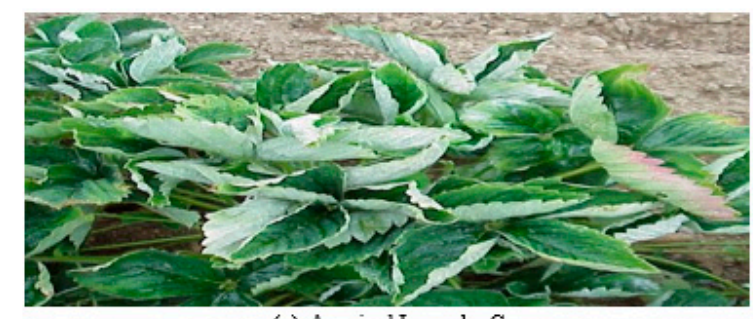

(a) Acquired Image by Camera

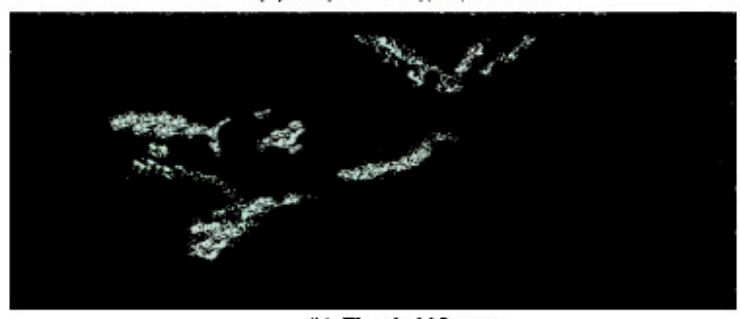

(b) Threshold Image

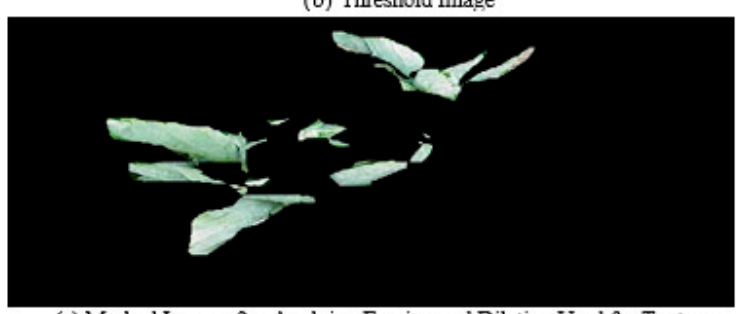

(c) Masked Image after Applying Erosion and Dilation Used for Texture

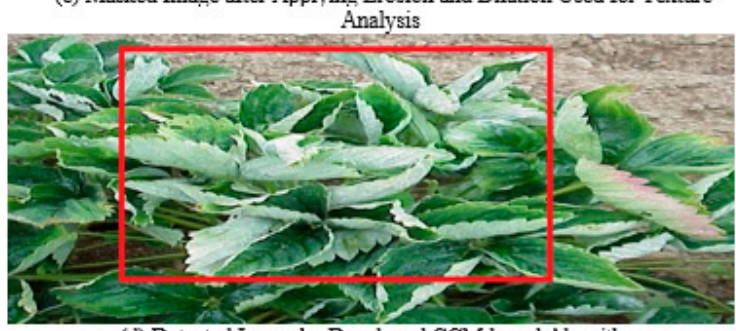

(d) Detected Image by Developed CCM-based Algorithm

Figure 7. Strawberry powdery mildew disease detection in real-time field condition: (a) acquired image, (b) threshold image, (c) masked image, and (d) PM detected image. 


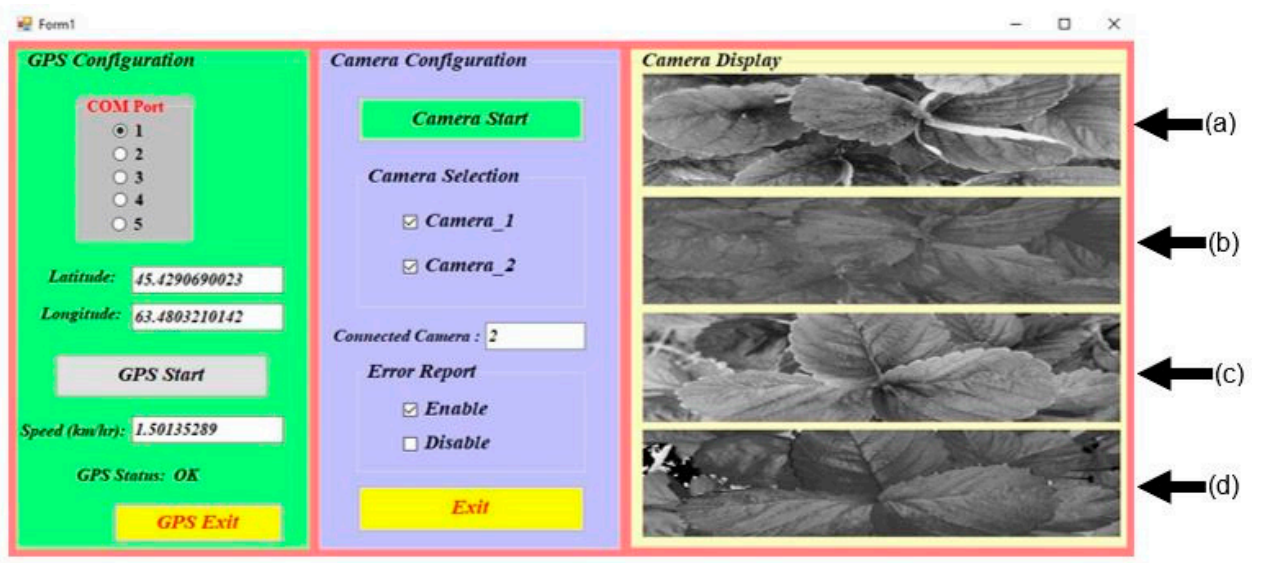

Figure 8. Machine vision-based powdery mildew disease detection software interface: (a): g-ratio image from camera 1, (b): hue image from camera 1, (c): g-ratio image from camera 2, and (d): hue image from camera 2.

\subsection{Statistical Analysis}

Linear regression analysis was used to compare the results of manual measurements (PM detected points) and real-time detection using the mobile machine vision system separately in each field by using Minitab ${ }^{\circledR} 18$ statistical software (Minitab ${ }^{\circledR}$ Inc., State College, PA, USA). The coefficient of determination $\left(R^{2}\right)$, mean absolute error (MAE), and root mean square error (RMSE) were calculated. A paired $t$-test was also used to compare the mean of two measurements in Minitab version 18.

\section{Results and Discussion}

\subsection{Laboratory Evaluation Results for ANN-Based PM Detection}

Table 5 shows ANN-based machine learning classifier performances based on internal, external, and cross validations with different image datasets. The model detected healthy, powdery mildew, and other diseases leaf images with higher accuracy in all cases of internal validations. The recall was calculated by the ratio of total correctly detected PM and total numbers of PM being detected (e.g., in case of internal validation: recall for PM detection $=784 /(6+784+10)$ and for calculation of precision for PM detection $=784 /(3+784+9))$. The highest recall $(98.00 \%)$, precision $(98.49 \%)$, and F-measure $(98.27 \%)$ were reported during internal validation and the lowest recall of $86.49 \%$ was calculated in external-III validation, and the lowest precision and F-measure of $85.27 \%$ and $86.22 \%$, respectively, were measured with external-I validation for strawberry PM detection. Laboratory evaluation suggested that the ANN classifier performed better with healthy and other diseases image classification resulting in fewer numbers of misclassifications, whereas a comparatively higher misclassification rate was obtained with powdery mildew images. 
Table 5. Laboratory-based evaluation of artificial neural network (ANN) classifier for strawberry powdery mildew (PM) detection.

\begin{tabular}{|c|c|c|c|c|c|c|c|c|}
\hline \multirow[b]{2}{*}{ Validations } & \multirow[b]{2}{*}{ Response } & \multicolumn{3}{|c|}{ Predicted } & \multirow[b]{2}{*}{ Total } & \multicolumn{3}{|c|}{ Performance (PM Detection) } \\
\hline & & Healthy & PM & $\begin{array}{c}\text { Other } \\
\text { Diseases }\end{array}$ & & $\begin{array}{c}\text { Recall } \\
(\%)\end{array}$ & $\begin{array}{l}\text { Precision } \\
(\%)\end{array}$ & $\begin{array}{c}\text { F-Measure } \\
(\%)\end{array}$ \\
\hline \multirow{3}{*}{ Internal } & Healthy & 790 & 3 & 7 & 800 & & & \\
\hline & PM & 6 & 784 & 10 & 800 & 98.00 & 98.49 & 98.27 \\
\hline & Other diseases & 4 & 9 & 787 & 800 & & & \\
\hline \multirow{3}{*}{ Fivefold Cross } & Healthy & 394 & 2 & 4 & 400 & & & \\
\hline & PM & 4 & 388 & 8 & 400 & 97.00 & 97.98 & 97.54 \\
\hline & Other diseases & 3 & 6 & 391 & 400 & & & \\
\hline \multirow{3}{*}{ External I ${ }^{a}$} & Healthy & 578 & 23 & 65 & 666 & & & \\
\hline & PM & 26 & 569 & 71 & 666 & 87.44 & 85.27 & 86.22 \\
\hline & Other diseases & 33 & 60 & 573 & 666 & & & \\
\hline \multirow{3}{*}{ External II ${ }^{\mathrm{b}}$} & Healthy & 587 & 24 & 55 & 666 & & & \\
\hline & PM & 16 & 579 & 71 & 666 & 86.94 & 86.81 & 86.87 \\
\hline & Other diseases & 19 & 64 & 583 & 666 & & & \\
\hline \multirow{3}{*}{ External III $^{\mathrm{c}}$} & Healthy & 586 & 29 & 51 & 666 & & & \\
\hline & PM & 32 & 576 & 58 & 666 & 86.49 & 86.75 & 86.63 \\
\hline & Other diseases & 27 & 59 & 580 & 666 & & & \\
\hline
\end{tabular}

External-I ${ }^{\text {a }}$ : training with Field I + Field II and validated with Field III; External-II ${ }^{\mathrm{b}}$ : training with Field I + Field III and validated with Field II; External-III ${ }^{c}$ : training with Field II + Field III and validated with Field I.

\subsection{Strawberry Field Real-Time Powdery Mildew Detection Results}

The machine vision-based powdery mildew disease detection system was tested at three strawberry field sites. The corresponding results are presented in Figure 9, Figure 10, and Figure 11 for field site-I, field site-II, and field site-III, respectively.

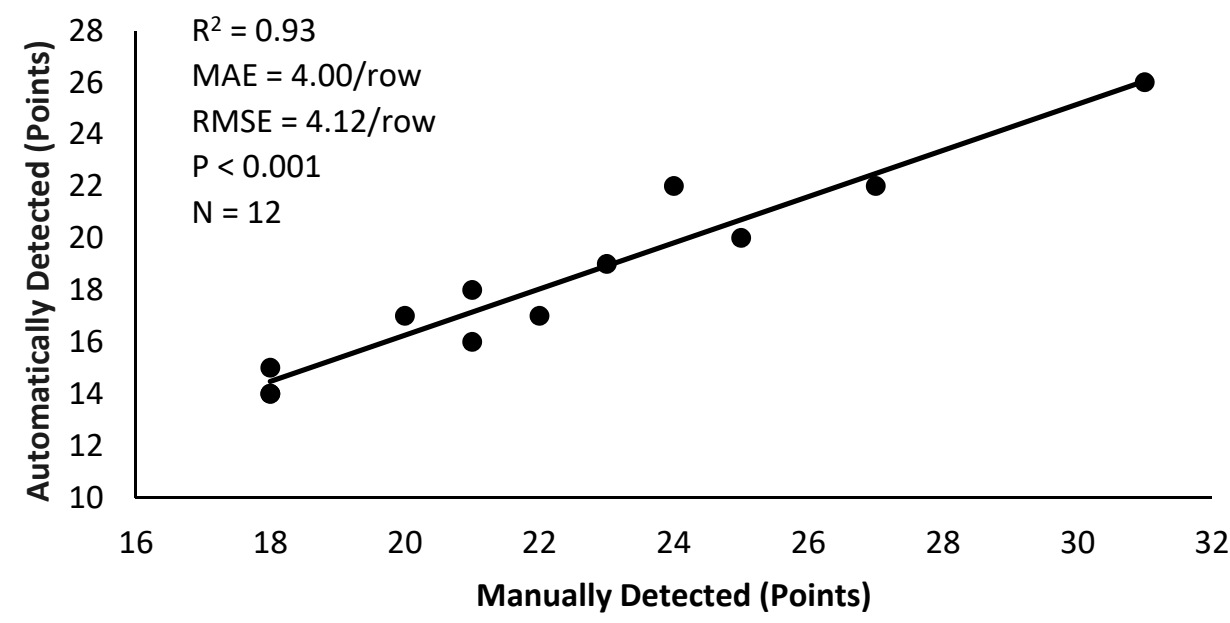

Figure 9. Correlation between manually and automatically detected points for field site I. 


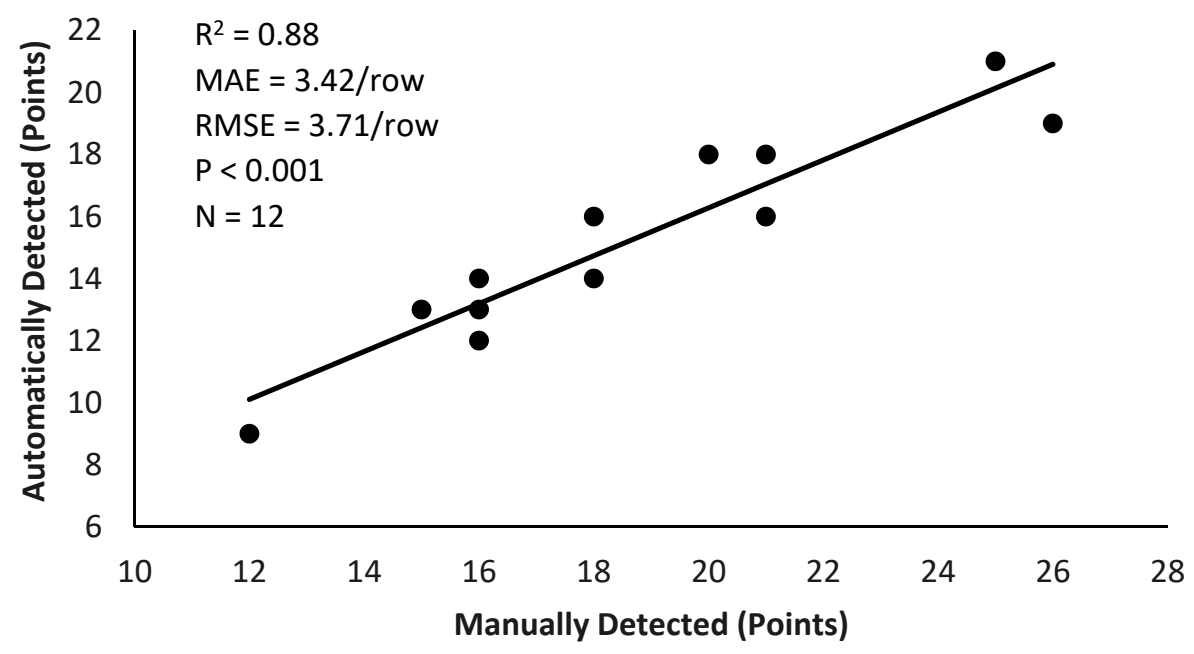

Figure 10. Correlation between manually and automatically detected points for field site II.

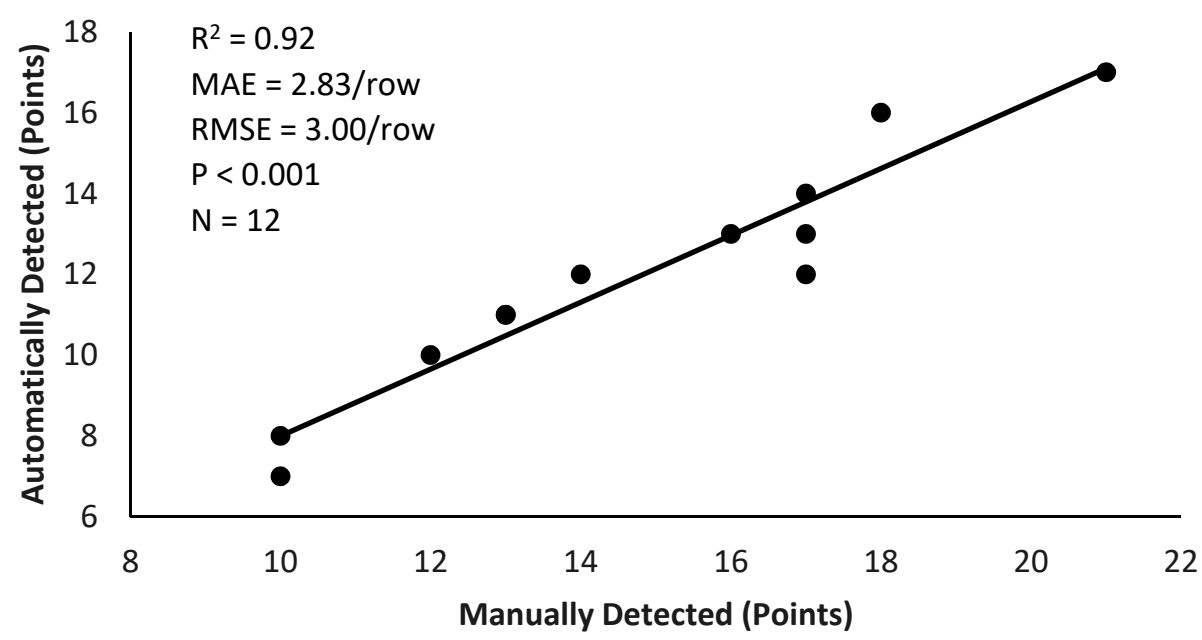

Figure 11. Correlation between manually and automatically detected points for field site III.

Linear regression of manually detected PM vs. real-time PM detection using the machine vision system suggests a highly significant correlation for field site-I $\left(R^{2}=0.93 ; p<0.001 ; \mathrm{N}=12\right)$ (Figure 9$)$. The system also showed a significant correlation with the other two fields (field site-II: $R^{2}=0.88 ; p<$ $0.001 ; \mathrm{N}=12$, field site-III: $R^{2}=0.92 ; p<0.001 ; \mathrm{N}=12$ ) (Figures 10 and 11). The MAE and RMSE were also calculated from all field tests. The results showed that higher MAE and RMSE were obtained from field site-I test (4.00/row and 4.12/row). Lower MAE and RMSE were recorded in validation with field site-III, with values of 2.83/row and 3.00/row, respectively. The MAE calculated values from three fields were lower than RMSE values because MAE does not give undue importance to large errors [35]. The co-efficient of determination $\left(R^{2}\right)$ was higher in field site-I and the MAE and RMSE values were also higher compared to the other two fields. This result was due to the larger number of PM-affected plants and longer length of rows in field site-I compared to the other field sites. The lowest $R^{2}$ value was 0.88 , generated from field site-II, due to overestimates by the machine vision system accounting white patch symptoms (i.e., spider mites) as powdery mildew disease. The underestimates were likely due to the higher density of plant leaves, resulting in powdery mildew-affected leaves being hidden under leaves. The variations in plant leaf density may have also contributed to the machine vision system accuracy. Palleja and Landers [36] noticed that the plant density could account for errors in 
image processing, while others have encountered issues with predicting harvest ripeness of blueberries using an image processing-based blue-ratio algorithm [37].

A direct comparison of manually and automatically detected powdery mildew disease in strawberry fields are presented in Figure 12.

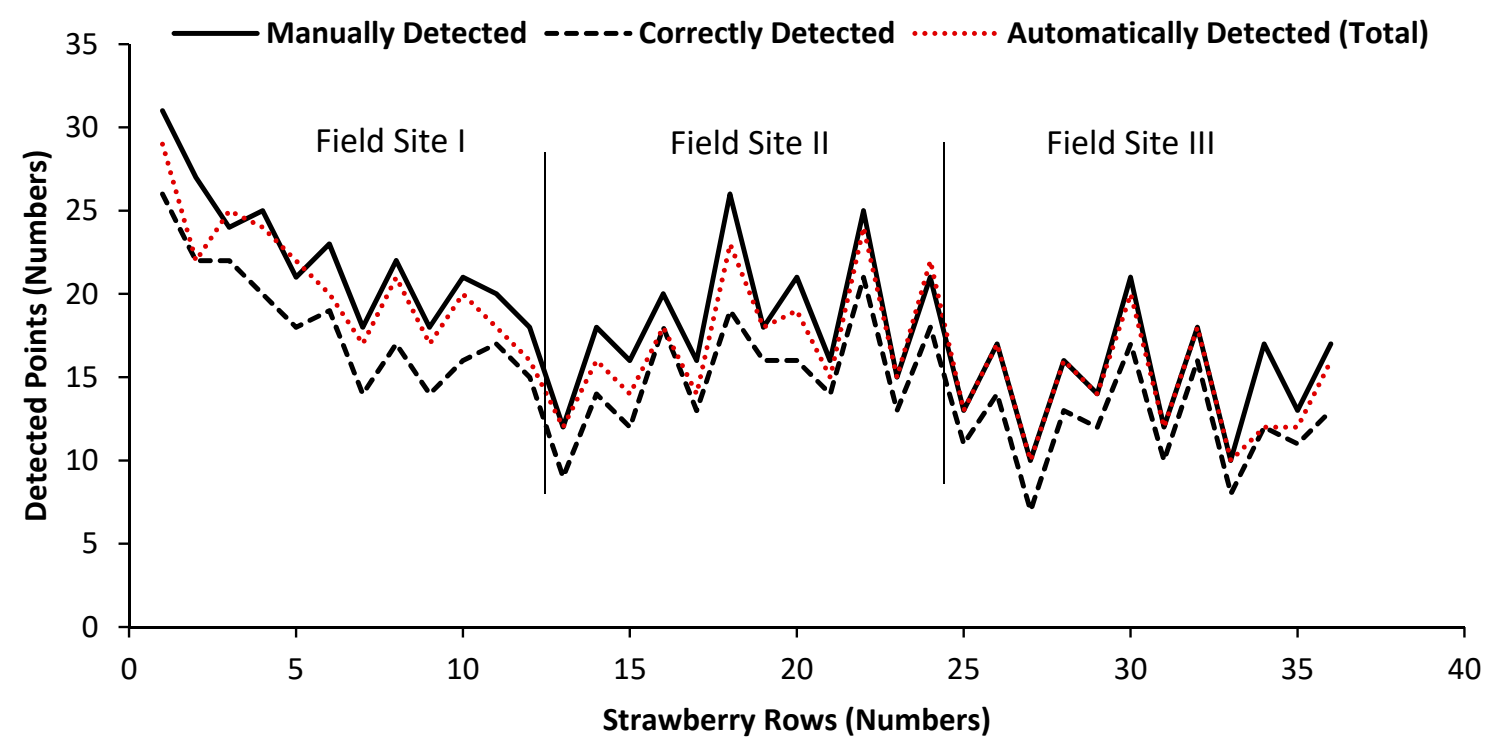

Figure 12. Strawberry powdery mildew disease detection comparison row by row between manually and automatically detected points.

The wind speed has direct effects upon real-time machine vision system performance under field conditions. Zhang and Chaisattapagon [38] developed a machine vision system for weed identification which was successful during laboratory experiments, but they pointed out that it was not practical for real-time weed detection, especially when a wind effect was considered. The wind speed can cause blurring boundaries in the images which becomes quite complicated for image analysis [39]. The more pronounced fluctuations for powdery mildew detections in our study were observed in the field site-II testing of strawberry rows (12-24 rows) under high wind speeds $\left(7-14 \mathrm{~km} \mathrm{~h}^{-1}\right)$. Comparatively, lower fluctuations were reported in field site-I (1-12 rows) results where the wind speed was $4-10 \mathrm{~km} \mathrm{~h}^{-1}$, followed by field site-III (25-36 rows) with a wind speed of 3-8 $\mathrm{km} \mathrm{h}^{-1}$. Since the wind speed was comparatively higher in field site-II, the movement of the branches and the leaves during real-time testing was a bit faster. Plant leaf movement during frame to frame image capture may have also resulted in a false match, which was similar to observations reported by Shrestha and Steward [40]. The number of affected plants were higher in field site-I compared to other two field sites due to longer row (220 m each) compared to other fields (180 m each) leading to misclassification rates of some strawberry rows being higher. Some of the misclassifications may be associated with spider mites that leave a white spider net over the leaves that the image processing algorithm identifies as PM.

The results of A paired-sample $t$-test suggested that a statistically significant difference existed between the two measurements (manual and automatic) for powdery mildew detection. At all field sites, manual identification of PM was always greater than the machine vision system implemented in the strawberry fields. The difference in mean detection of PM between manual and machine vision (automatic) at field site-I was 4.00 (95\% CI, 3.34 to $4.66 ; p<0.001)$, for field site-II, it was 3.42 (95\% CI, 2.46 to $4.37 ; p<0.001$ ), and for field site-III, it was 2.83 (95\% CI, 2.18 to 3.48; $p<0.001$ ) (Table 6). 
Table 6. Pair-wise $t$-test for manually and automatically powdery mildew disease detection.

\begin{tabular}{|c|c|c|c|c|c|}
\hline Fields & Detections & Mean (Points) & S.D. (Points) & Mean Diff. (Points) & $p$-Value \\
\hline \multirow{2}{*}{ Field site-I } & Manual & 22.33 & 3.96 & \multirow[b]{2}{*}{4.00} & \multirow{2}{*}{$<0.001^{\mathrm{a}}$} \\
\hline & Automatic & 18.33 & 3.65 & & \\
\hline \multirow{2}{*}{ Field site-II } & Manual & 18.67 & 4.12 & \multirow{2}{*}{3.42} & \multirow{2}{*}{$<0.001^{\mathrm{a}}$} \\
\hline & Automatic & 15.25 & 3.39 & & \\
\hline \multirow{2}{*}{ Field site-III } & Manual & 14.83 & 3.38 & \multirow{2}{*}{2.83} & \multirow{2}{*}{$<0.001^{\mathrm{a}}$} \\
\hline & Automatic & 12.00 & 2.92 & & \\
\hline
\end{tabular}

${ }^{a}$ Significant at a probability level of $p=0.05$.

The real-time field evaluation results demonstrated that the machine vision image processing system could achieve a high recall $(82.09 \%)$, precision $(87.65 \%)$, and F-measure values $(85.09 \%)$, specifically at field site-I (Table 7). The accuracy parameters at the other two field sites were comparable, despite having differences in field row lengths and wind conditions. Two types of statistical errors were noticed during the field evaluations (e.g., type-I error and type-II error). The type-I error, also called a false positive, and the type-II error, known as a false negative, are likely to occur under conditions when variables, such as climate, lighting, and environmental conditions, cannot be well controlled. In type-I error, machine vision system detected PM diseases when there were healthy or other diseased leaves present. The type-II errors occurred when the machine vision system confirmed no PM disease on the leaf but the manual detection identified it as being present. In the long run, reducing type-II error is important in order to minimize the spread of PM from one plant to another. In this experiment, the type-II error was comparatively higher than type-I error at field site-I and field site-II because the machine vision system mistook for PM disease detection and accounted PM as spider mites in some spots.

Table 7. Real-time field evaluation results of developed machine vision system.

\begin{tabular}{ccccccc}
\hline & \multicolumn{5}{c}{ Accuracy Parameters [s] } \\
\cline { 2 - 7 } & $\mathbf{T}_{\mathbf{p}}$ (Points) & $\mathbf{F}_{\mathbf{p}}$ (Points) & $\mathbf{F}_{\mathbf{n}}$ (Points) & Recall (\%) & Precision (\%) & F-measure (\%) \\
\hline Field I & 220 & 31 & 48 & 82.09 & 87.65 & 85.09 \\
Field II & 183 & 27 & 41 & 81.70 & 87.14 & 84.64 \\
Field III & 144 & 26 & 34 & 80.90 & 84.71 & 82.97 \\
\hline
\end{tabular}

$[\mathrm{s}] \mathrm{T}_{\mathrm{p}}$ means true positive; $\mathrm{F}_{\mathrm{p}}$ means false positive; $\mathrm{F}_{\mathrm{n}}$ means false negative.

Although our real-time machine vision imaging system provided good insights for field-based detection of PM in strawberry fields, a number of challenges were also identified. Previous studies also identified challenges on their experiments in field conditions [41-43]. Jeon et al. [42] was able to detect $72.6 \%$ of crop correctly using ANN with a real-time crop and weed segmentation algorithm. Other researchers attempted to overcome the issues arising under field conditions by developing an environmentally adaptive segmentation algorithm, but it was only able to correctly identify $45 \%$ to $67 \%$ of tomato cotyledons [43]. This study detected over $80 \%$ of powdery mildew disease correctly in the three commercial strawberry fields tested due to errors caused by uncontrolled environment. A high frame per second (FPS) camera would have reduced effects of windy conditions in the field experiments but managing for other sources of error for real-time detection is still a major area of study. Faster processing also needs to be considered while using high-resolution images.

\subsection{Prescription Map of Field Evaluations}

Strawberry powdery mildew disease detection results from the three commercial strawberry field sites were mapped in ArcGIS 10.5 software (Figure 13, Figure 14, and Figure 15). The map consists of real-time machine vision system detected points that are marked with red bullets and manually 
detected points, represented by a star. The overlaid markers were georeferenced and compared to evaluate the accuracy of the machine vision detection system relative to the manual detection. Subjective analysis of prescription maps indicated that the system detected powdery mildew disease with an $82.09 \%, 81.70 \%$, and $80.90 \%$ accuracy for field site-I, field site-II, and field site-III, respectively. The accuracies were calculated using the ratio of total correctly detected points with the machine vision system relative to the total manual detected points. Figure 13 identified that the presence of powdery mildew was greater in the western and eastern parts of field site-I compared to the central portion of the field. Correspondingly, Figure 14 identified that the western and central western parts of field site-II were more severely affected than other areas, and Figure 15 indicated that field site-III was severely impacted by powdery mildew in the eastern parts of the site. The map revealed that field site III (Figure 15) strawberry plants were less affected by powdery mildew disease compared to field site I (Figure 13) and field site II (Figure 14). The goal of generating the prescription maps is to provide the true scenario of the developed detection system's effectiveness for PM monitoring and to help in understanding the distribution of disease throughout the fields. Another reason is to provide decision support for the spraying machine, which will be considered in our future study.

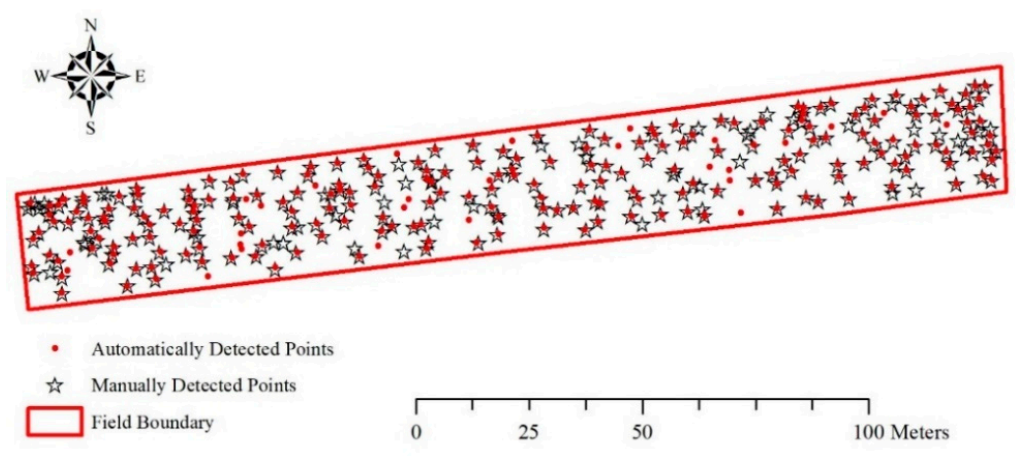

Figure 13. Field site I (powdery mildew disease detection map for site-specific management).

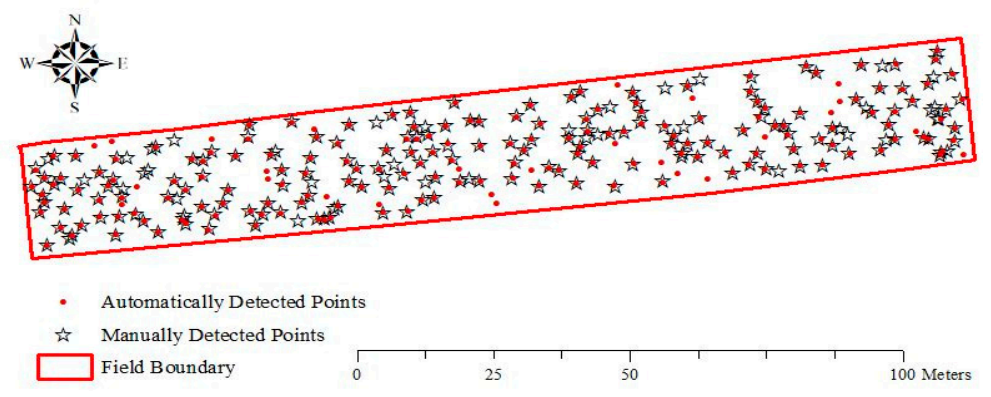

Figure 14. Field site II (powdery mildew disease detection map for site-specific management).

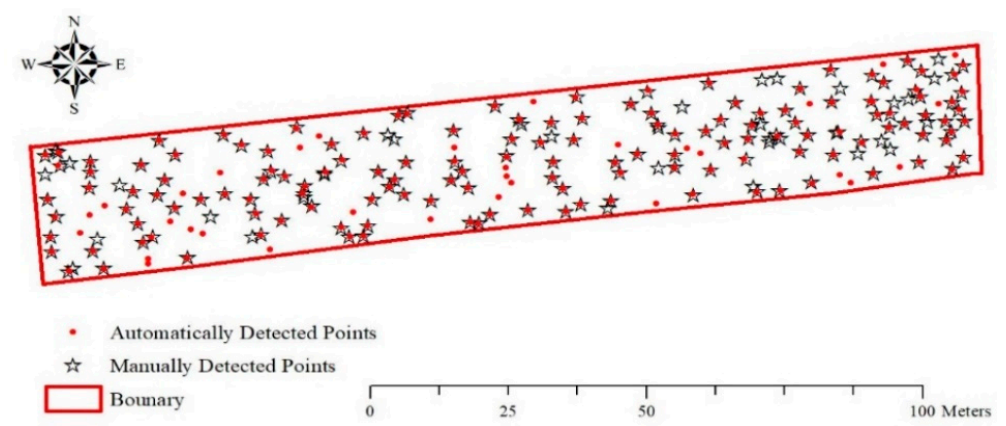

Figure 15. Field site III (powdery mildew disease detection map for site-specific management). 
Overall, a total of $17.91 \%$ powdery mildew affected points were missed in field site-I compared to $18.30 \%$ points and $19.10 \%$ points in field site-II and field site-III, respectively. In contrast, the real-time machine vision system inaccurately detected powdery mildew points by $10.37 \%, 10.76 \%$, and $12.75 \%$ for field site-I, field, site-II and field site-III, respectively. Despite our system can only detect over $80 \%$ of PM disease in the field evaluations as stated earlier, the developed vision system can be used onsite since it saves time and costs for PM disease monitoring with reliable observation. An over $80 \%$ of accuracy is sufficient to be claimed as useful for the strawberry growers because till date, there is no such technology available, however, improvement of the system is expected in the future considering various environmental factors. Additionally, manual monitoring is a time-consuming and costly approach since the diagnosis requires very careful observation. A higher risk of human error is also associated with manual monitoring due to the scout's fatigue for continuously working in the field. On the other hand, this custom-based system is a feasible and reliable option for minimizing PM disease outbreak through monitoring symptoms rapidly and providing warnings about disease risk. Prescription maps have been used by many researchers as a means of visually reporting the detection and site-specific management results of their machine vision systems, particularly for applications of variable rate spraying technologies in different cropping systems [44-46], crop disease mapping [47], weed mapping [48,49], site-specific management [50-52], and spot applications [53,54]. Miller et al. [46] applied granular fertilizer in citrus and observed that GPS map-based control were similar to those found for real-time control. Prescription maps also incorporate well with real-time machine vision systems in different cropping systems to detect weeds, bare spots, and fruits $[53,55,56]$. Hence, the generation of prescription map based on disease outbreaks in the field could be used to support site-specific management for variable rate fungicide spraying by strawberry growers. In this study, it is aimed to detect the suspected region of the strawberry PM disease symptom-based on a mobile machine vision system, and it was possible that automatically detected PM symptom area was visible by the naked eyes of field scouts. It can improve the detection performance by reducing the time and cost as compared to the manual monitoring and also by minimizing scout's fatigue in the field diagnosis.

\section{Conclusions}

Field-based evaluation of strawberry fields via a novel real-time mobile machine vision powdery mildew detection system, using image texture analysis, was successful. The real-time vision system detected PM disease with F-measure values averaging $84.23 \%$ across three commercial strawberry field sites. A custom CCM-based image processing algorithm in conjunction with ANN was used to detect the PM disease in strawberry fields. Two RGB cameras were used to continuously capture images from the fields. Acquired images were converted to green ratio, hue, saturation, and intensity images before generating CCM from each. The CCM was generated from each converted image and then, textural features were extracted. A total of 23 texture features, along with ANN classifier, were utilized in the machine vision system development. Manually measured powdery mildew detected points were compared with the real-time PM detected points using the machine vision system. Results of linear regression plots showed significant correlations between manually and automatically detected PM points. The MAE and RMSE of the detection results were 4.00, 3.42, and 2.83 per row and 4.12, 3.71, and 3.00 per row for field site-I, field site-II, and field site-III, respectively. Real-time field evaluation results of this study reported that the developed machine vision system achieved a high recall of $82.09 \%$, precision of $87.65 \%$, and F-measure of $85.09 \%$ during testing at field site-I compared to other two field sites. The automatic PM disease detection system was fairly accurate; however, some misclassifications were also reported in places. Environmental variability, especially spatial variability of wind speeds, effects of leaf overlap or differences in density, and presence of spider mites, resulted in slightly higher misclassification rates than desired. The advancement of a commercial real-time machine vision aided PM detection system needs to consider how to address these variables in future studies. Despite the challenges identified in our study, the relatively low cost of developing this system and the ease of 
implementation demonstrated the real potential for providing a real-time decision support system for strawberry growers.

Author Contributions: Conceptualization, M.S.M., T.J.E., Q.U.Z., and Y.K.C.; methodology, M.S.M. and Y.K.C.; software, M.S.M.; validation, M.S.M.; formal analysis, M.S.M.; investigation, Q.U.Z., T.J.E., G.W.P., and B.P.; resources, Q.U.Z.; data curation, M.S.M.; writing—original draft preparation, M.S.M.; writing—review and editing, M.S.M., Q.U.Z., T.J.E., Y.K.C., G.W.P., and B.P.; visualization, M.S.M.; supervision, T.J.E. and Q.U.Z.; project administration, Q.U.Z.; funding acquisition, Q.U.Z. All authors have read and agreed to the published version of the manuscript.

Funding: This research was financially supported by the following grant sources: Doug Bragg Enterprises, Dalhousie University, Natural Sciences and Engineering Research Council of Canada Discovery Grants Program (RGPIN-2017-05815), and Nova Scotia Graduate Research and Innovation Scholarship.

Acknowledgments: The authors would like to thank Carl Bragg (President, DBE), Doug Wyllie (Farm Manger, Bragg Lumber Company), Curtis Millen (Owner of Millen Farm Ltd.), Scott Read (Senior Instructor), and the Precision Agriculture Team (especially, Negar Sharifi Mood (research assistant) and Derrick Ouma (summer student)) of Dalhousie University for their support during experiments.

Conflicts of Interest: The authors declare no conflict of interest.

\section{References}

1. Maas, J. Compendium of Strawberry Diseases; The American Phytopathological Society Press: St. Paul, MN, USA, 1998.

2. Pertot, I.; Zasso, R.; Amsalem, L.; Baldessari, M.; Angeli, G.; Elad, Y. Integrating biocontrol agents in strawberry powdery mildew control strategies in high tunnel growing systems. Crop. Prot. 2008, 27, $622-631$. [CrossRef]

3. Xiao, C.L.; Chandler, C.K.; Price, J.F.; Duval, J.R.; Mertely, J.C.; Legard, D.E. Comparison of epidemics of Botrytis fruit rot and powdery mildew of strawberry in large plastic tunnel and field production systems. Plant. Dis. 2001, 85, 901-909. [CrossRef]

4. Nelson, M.D.; Gubler, W.D.; Shaw, D.V. Inheritance of powdery mildew resistance in greenhouse-grown versus field-grown California strawberry progenies. Phytopathology 1995, 85, 421-424. [CrossRef]

5. Amsalem, L.; Freeman, S.; Rav-David, D.; Nitzani, Y.; Sztejnberg, A.; Pertot, I.; Elad, Y. Effect of climatic factors on powdery mildew caused by Sphaerotheca macularis f. sp. fragariae on strawberry. Eur. J. Plant. Pathol. 2006, 114, 283-292. [CrossRef]

6. Spencer, D. Powdery mildew of strawberries. In Spencer DM.; The Powdery Mildews Academic Press: New York, NY, USA, 1978; pp. 355-358.

7. Asalf, B. Strawberry Powdery Mildew: Pathogen Biology, Ecology and Components of Disease Resistance in the Host. Ph.D. Thesis, University of Life Sciences, Ås, Norway, 2013.

8. Liu, B. Sustainable Strawberry Production and Management including Control of Strawberry Powdery Mildew. Ph.D. Thesis, University of Hertfordshire, Hatfield, UK, 2017.

9. Zhang, J.; Pu, R.; Yuan, L.; Wang, J.; Huang, W.; Yang, G. Monitoring powdery mildew of winter wheat by using moderate resolution multi-temporal satellite imagery. PLoS ONE 2014, 9, e93107. [CrossRef]

10. Al-Hiary, H.; Bani-Ahmad, S.; Reyalat, M.; Braik, M.; ALRahamneh, Z. Fast and accurate detection and classification of plant diseases. Int. J. Comput. Appl. 2011, 17, 31-38. [CrossRef]

11. Sankaran, S.; Mishra, A.; Ehsani, R.; Davis, C. A review of advanced techniques for detecting plant diseases. Comput. Electron. Agric. 2010, 71, 1-13. [CrossRef]

12. Barbedo, J.G.A. A review on the main challenges in automatic plant disease identification based on visible range images. Biosyst. Eng. 2016, 144, 52-60. [CrossRef]

13. Romeo, J.; Guerrero, J.M.; Montalvo, M.; Emmi, L.; Guijarro, M.; Gonzalez-de-Santos, P.; Pajares, G. Camera sensor arrangement for crop/weed detection accuracy in agronomic images. Sensors 2013, 13, 4348-4366. [CrossRef]

14. Pajares, G.; García-Santillán, I.; Campos, Y.; Montalvo, M.; Guerrero, J.M.; Emmi, L.; Romeo, J.; Guijarro, M.; Gonzalez-de-Santos, P. Machine-vision systems selection for agricultural vehicles: A guide. J. Imaging 2016, 2, 34. [CrossRef]

15. Lee, W.S.; Slaughter, D.C.; Giles, D.K. Robotic weed control system for tomatoes. Precis. Agric. 1999, 1, 95-113. [CrossRef] 
16. Sabzi, S.; Abbaspour-Gilandeh, Y.; Javadikia, H. Machine vision system for the automatic segmentation of plants under different lighting conditions. Biosyst. Eng. 2017, 161, 157-173. [CrossRef]

17. Pydipati, R.; Burks, T.F.; Lee, W.S. Statistical and neural network classifiers for citrus disease detection using machine vision. Trans. Am. Soc. Agric. Eng. 2005, 48, 2007-2014. [CrossRef]

18. Pydipati, R.; Burks, T.F.; Lee, W.S. Identification of citrus disease using color texture features and discriminant analysis. Comput. Electron. Agric. 2006, 52, 49-59. [CrossRef]

19. Al Bashish, D.; Braik, M.; Bani-Ahmad, S. Detection and classification of leaf diseases using K-means-based segmentation and neural-networks-based classification. Inf. Technol. J. 2011, 10, 267-275. [CrossRef]

20. Arivazhagan, S.; Shebiah, R.N.; Ananthi, S.; Vishnu Varthini, S. Detection of unhealthy region of plant leaves and classification of plant leaf diseases using texture features. Agric. Eng. Int. CIGR J. 2013, 15, 211-217.

21. Mahmud, M.S.; Chang, Y.K.; Zaman, Q.U.; Esau, T.J. Detection of strawberry powdery mildew disease in leaf using image texture and supervised classifiers. In Proceedings of the CSBE/SCGAB 2018 Annual Conference, Guelph, ON, USA, 22-25 July 2018.

22. Mahmud, M.S.; Chang, Y.K.; Zaman, Q.U.; Esau, T.J.; Price, G.W.; Prithiviraj, B. Development of an artificial cloud lighting condition system using machine vision for strawberry powdery mildew disease detection. Comput. Electron. Agric. 2019, 158, 219-225. [CrossRef]

23. Shearer, S.A.; Holmes, R.G. Plant identification using color co-occurrence matrices. Trans. ASAE 1990, 33, 1237-1244. [CrossRef]

24. Choudhary, G.M.; Gulati, V. Advance in Image Processing for Detection of Plant Diseases. Int. J. Adv. Res. Comput. Sci. Softw. Eng. 2015, 5, 135-141.

25. Yang, J.; Yang, T.; Miao, T.; Zhu, C.; Shen, Q.; Peng, Y.; Mei, P.; Dang, Y. Recognition of powdery mildew disease of strawberry leaves based on convolutional neural network. Jiangsu J. Agric. Sci. 2018, 34, 527-532.

26. Meng, Q.; Qiu, R.; He, J.; Zhang, M.; Ma, X.; Liu, G. Development of agricultural implement system based on machine vision and fuzzy control. Comput. Electron. Agric. 2015, 112, 128-138. [CrossRef]

27. Gonzalez, R.C.; Wood, R.E. Digital Image Processing, 4th ed.; Pearson, Inc.: New York, NY, USA, 2018.

28. Chang, Y.K.; Zaman, Q.U.; Schumann, A.W.; Percival, D.C.; Esau, T.J.; Ayalew, G. Development of color co-occurrence matrix based machine vision algorithms for wild blueberry fields. Appl. Eng. Agric. 2012, 28, 315-323. [CrossRef]

29. Haralick, R.M.; Shanmugam, K.; Dinstein, I.H. Textural features for image classification. IEEE Trans. Syst. Man Cybern. 1973, 610-621. [CrossRef]

30. Dandawate, Y.; Kokare, R. An automated approach for classification of plant diseases towards development of futuristic decision support system in Indian perspective. In Proceedings of the 2015 International Conference on Advances in Computing, Communications and Informatics (ICACCI), Kochi, India, 10-13 August 2015; IEEE: Los Alamitos, CA, USA, 2015; pp. 794-799.

31. Shin, J.; Chang, Y.K.; Heung, B.; Nguyen-Quang, T.; Price, G.W.; Al-Mallahi, A. Effect of directional augmentation using supervised machine learning technologies: A case study of strawberry powdery mildew detection. Biosyst. Eng. 2020, 194, 49-60. [CrossRef]

32. Chang, Y.K.; Mahmud, M.; Shin, J.; Nguyen-Quang, T.; Price, G.W.; Prithiviraj, B. Comparison of image texture based supervised learning classifiers for strawberry powdery mildew detection. AgriEngineering 2019, 1, 434-452. [CrossRef]

33. Farooque, A.A.; Zaman, Q.U.; Nguyen-Quang, T.; Groulx, D.; Schumann, A.W.; Chang, Y.K. Development of a predictive model for wild blueberry harvester fruit losses during harvesting using artificial neural network. Appl. Eng. Agric. 2016, 32, 725-738.

34. NCDIA. National Climate Data and Information Archive; Environment Canada: Ottawa, ON, Canada, 2018.

35. Meade, N. Evidence for the selection of forecasting methods. J. Forecast. 2000, 19, 515-535. [CrossRef]

36. Palleja, T.; Landers, A.J. Real time canopy density estimation using ultrasonic envelope signals in the orchard and vineyard. Comput. Electron. Agric. 2015, 115, 108-117. [CrossRef]

37. Ali, S.; Zaman, Q.U.; Farooque, A.A.; Schumann, A.W.; Udenigwe, C.C.; Esau, T.; Chang, Y.K. Potential use of digital photographic technique to examine wild blueberry ripening in relation to time of harvest. Appl. Eng. Agric. 2018, 34, 299-308. [CrossRef]

38. Zhang, N.; Chaisattapagon, C. Effective criteria for weed identification in wheat fields using machine vision. Trans. ASAE 1995, 38, 965-974. 
39. Guyer, D.E.; Miles, G.E.; Schreiber, M.M.; Mitchell, O.R.; Vanderbilt, V.C. Machine vision and image processing for plant identification. Trans. ASAE 1986, 29, 1500-1507. [CrossRef]

40. Shrestha, D.S.; Steward, B.L. Automatic corn plant population measurement using machine vision. Trans. ASAE 2003, 46, 559. [CrossRef]

41. Jafari, A.; Mohtasebi, S.S.; Jahromi, H.E.; Omid, M. Weed detection in sugar beet fields using machine vision. Int. J. Agric. Biol. 2006, 8, 602-605.

42. Jeon, H.Y.; Tian, L.F.; Zhu, H. Robust crop and weed segmentation under uncontrolled outdoor illumination. Sensors 2011, 11, 6270-6283. [CrossRef]

43. Tian, L.F.; Slaughter, D.C. Environmentally adaptive segmentation algorithm for outdoor image segmentation. Comput. Electron. Agric. 1998, 21, 153-168. [CrossRef]

44. Carrara, M.; Comparetti, A.; Febo, P.; Orlando, S. Spatially variable rate herbicide application on durum wheat in Sicily. Biosyst. Eng. 2004, 87, 387-392. [CrossRef]

45. O'Shaughnessy, S.A.; Evett, S.R.; Colaizzi, P.D. Dynamic prescription maps for site-specific variable rate irrigation of cotton. Agric. Water Manag. 2015, 159, 123-138. [CrossRef]

46. Miller, W.M.; Schumann, A.W.; Whitney, J.D. Evaluating variable rate granular fertilizer technologies in florida citrus. Proc. Fla. State Hortic. Soc. 2004, 117, 161-166.

47. Yang, C.; Odvody, G.N.; Thomasson, J.A.; Isakeit, T.; Nichols, R.L. Change detection of cotton root rot infection over 10-year intervals using airborne multispectral imagery. Comput. Electron. Agric. 2016, 123, 154-162. [CrossRef]

48. de Castro, A.I.; Torres-Sánchez, J.; Peña, J.M.; Jiménez-Brenes, F.M.; Csillik, O.; López-Granados, F. An automatic random forest-obia algorithm for early weed mapping between and within crop rows using UAV imagery. Remote Sens. 2018, 10, 285. [CrossRef]

49. López-Granados, F.; Torres-Sánchez, J.; Serrano-Pérez, A.; de Castro, A.I.; Mesas-Carrascosa, F.J.; Peña, J.M. Early season weed mapping in sunflower using UAV technology: Variability of herbicide treatment maps against weed thresholds. Precis. Agric. 2016, 17, 183-199. [CrossRef]

50. Amaral, L.R.; Trevisan, R.G.; Molin, J.P. Canopy sensor placement for variable-rate nitrogen application in sugarcane fields. Precis. Agric. 2018, 19, 147-160. [CrossRef]

51. Brown, R.B.; Steckler, J.P. Prescription maps for spatially variable herbicide application in no-till corn. Trans. ASAE 1995, 38, 1659-1666. [CrossRef]

52. Fleming, K.L.; Westfall, D.G.; Wiens, D.W.; Brodahl, M.C. Evaluating farmer defined management zone maps for variable rate fertilizer application. Precis. Agric. 2000, 2, 201-215. [CrossRef]

53. Esau, T.J.; Zaman, Q.U.; Chang, Y.K.; Schumann, A.W.; Percival, D.C.; Farooque, A.A. Spot-application of fungicide for wild blueberry using an automated prototype variable rate sprayer. Precis. Agric. 2014, 15, 147-161. [CrossRef]

54. Zaman, Q.U.; Esau, T.J.; Schumann, A.W.; Percival, D.C.; Chang, Y.K.; Read, S.M.; Farooque, A.A. Development of prototype automated variable rate sprayer for real-time spot-application of agrochemicals in wild blueberry fields. Comput. Electron. Agric. 2011, 76, 175-182. [CrossRef]

55. Tian, L. Development of a sensor-based precision herbicide application system. Comput. Electron. Agric. 2002, 36, 133-149. [CrossRef]

56. Zhang, F.; Zaman, Q.U.; Percival, D.C.; Schumann, A.W. Detecting bare spots in wild blueberry fields using digital color photography. Appl. Eng. Agric. 2010, 26, 723-728. [CrossRef]

(C) 2020 by the authors. Licensee MDPI, Basel, Switzerland. This article is an open access article distributed under the terms and conditions of the Creative Commons Attribution (CC BY) license (http://creativecommons.org/licenses/by/4.0/). 